\title{
On the Origin and Diagnostic Criteria of Olfactory Neuroblastoma
}

\author{
Hidetoshi Okabe, Takako Okubo and Yukio Ochi \\ Department of Laboratory Medicine, Shiga University of Medical Science, Seta Tsukinowa-cho Otsu, 520-2I
}

Received for publication February 17, 1997

The origin and diagnostic criteria of olfactory neuroblastoma are still under dispute. To solve these problems, seven cases of olfactory neuroblastomas satisfying diagnostic criteria of Choi and Anderson were analyzed immunohistochemically by using antibodies to markers expressed in developing and mature human olfactory placode-derived neurons such as keratin, a 34 kDa epithelial membrane glycoprotein, luteinizing-hormonereleasing-hormone (LHRH) and to other neural tissue markers. Ultrastructural analysis was also carried out. Five cases were identified as neuroblastomas because neurites were disclosed in them. All of these five cases had widespread immunoreactivity to an antibody to a $34 \mathrm{kDa}$ epithelial membrane glycoprotein (Ber-EP4) in the tumor cell bodies and/or neuritic processes. They also contained keratin positive cells. LHRH was demonstrated in two of these Ber-EP4 positive neuroblastomas. The spectrum of immunohistochemical findings of these five cases was identical to the normal neuroblasts arising from olfactory placode.

Accordingly, it is concluded that neuroblastoma of true olfactory placodal origin does exist. The diagnostic criteria of this tumor is as follows: demonstration of neurites and immunoreactivity to Ber-EP4 and/or LHRH. Keratin is not necessary to regard as an evidence of epithelial differentiation in this tumor.

Key words: Olfactory neuroblastoma, Ber-EP4, Luteinizing-hormone-releasing-hormone, Ultrastructure

\section{Introduction}

According to WHO's classification, olfactory neuroblastoma is defined as a neoplasm predominantly composed of neuroblastic cells presumed to be derived from precursor cells of nasal placode (neuroepithelium) that is the source of olfactory sensory neuron [5], but its origin is still under dispute $[2,5,17,19]$. Unlike other neuroblastomas, epithelial differentiation has been reported in a variant of this tumor, aesthesioneuroepithelioma, which has been deduced from the ability of the precursor cells to differentiate into both neuronal and epithelial components $[5,6,9,17,21]$. Epithelial markers such as keratin has been demonstrated in such cases [5, 17, 21]. However, coexistence of epithelial and neural tissue markers has been regarded as diagnostic evidence of neuroendocrine carcinoma in other organs [1, 4, 24] and distinction between poorly differentiated neuroendocrine carcinoma and poorly differentiated

Correspondence to: Hidetoshi Okabe MD., Division of Surgical Pathology, Department of Laboratory Medicine, Shiga University of Medical Science, Seta, Otsu 520-21, Japan. olfactory neuroblastoma is controversial $[2,5,19]$. Differentiation from paragangliomas is also a matter of dispute.

To resolve controversy on the origin of this putative neoplastic entity, it is necessary to analyze morphologic and immunohistochemical findings of the so-called olfactory neuroblastoma in comparison with normal olfactory placode-derived neurons through their development [12$14,16,18,25]$. In this paper, we describe the results of immunohistochemical and ultrastructural analysis of socalled olfactory neuroblastomas satisfying the criteria of Choi and Anderson [3], and compare the findings with the phenotype specific to normal embryonic and mature olfactory sensory neurons and hypothalamic neurons derived from olfactory placode, such as $34 \mathrm{kDa}$ epithelial membrane glycoprotein detected by Ber-EP4 and LHRH and keratin $[13,14,16,18,25$,$] .$

\section{Materials and Methods}

Seven cases of olfactory neuroblastomas diagnosed according to the immunohistochemical criteria of Choi and Anderson [3] were used for this study (Table 1). 
Table 1. Cases used for the analysis

\begin{tabular}{|c|c|c|c|}
\hline \multicolumn{3}{|c|}{ Age/Sex } & \multirow{2}{*}{$\begin{array}{l}\text { Location of the tumor } \\
\text { nasal cavity, cribriform sinus, cranial basis }\end{array}$} \\
\hline 1 & 85 & $\mathbf{F}$ & \\
\hline 2 & 55 & $\mathbf{M}$ & cribriform and sphenoid sinuses, cranial basis \\
\hline 3 & 56 & $\mathbf{M}$ & $\begin{array}{l}\text { nasal cavity, cribriform and maxillary sinuses, } \\
\text { cranial basis }\end{array}$ \\
\hline 4 & 58 & $\mathbf{M}$ & nasal cavity, cribriform sinus, sphenoid sinus \\
\hline 5 & 46 & $\mathbf{M}$ & nasal cavity, cribriform sinus, cranial basis \\
\hline 6 & 59 & $\mathbf{M}$ & nasal cavity, cribriform sinus, cranial basis \\
\hline 7 & 47 & $\mathbf{F}$ & nasal cavity \\
\hline
\end{tabular}

Formalin fixed and paraffin embedded tumor tissues were processed for light microscopic preparation as well as immunohistochemical analysis using primary antibodies listed in Table 2. All of the immunohistochemical stainings were carried out by a peroxidase conjugated avidin biotin system (DAKO Co. Ltd) and coloration was conducted with 3,3'-diaminobenzidine. Before the staining of keratin, neurofilament (NF), and synaptophysin, deparaffinized slides were treated with $0.1 \%$ trypsin in a $0.2 \%$ aqueous solution of $\mathrm{CaCl}_{2}$ for $16 \mathrm{~min}$ at $37^{\circ} \mathrm{C}$ and slides for $\mathrm{LHRH}$ staining were heated at $95^{\circ} \mathrm{C}$ in $0.01 \mathrm{M}$ citrate buffer ( $\mathrm{pH} \mathrm{6.0)}$ for $7 \mathrm{~min}$ using a microwave cooking range. Fresh tissues of four cases 1, 5, 6 and 7 were fixed in $2 \%$ glutaraldehyde and paraffin blocks of remaining 3 cases were dewaxed and processed for electron microscopic observation. After the postfixation in 1\% osmium tetraoxide, specimens were dehydrated in ethanol and QY1 (Oken Co. Ltd) and embedded in Spurr (Oken Co. Ltd). Ultrathin sections were stained by uranyl acetate and lead citrate and observed by Jeol $1200 \mathrm{EX}$ (Nihon Denshi Co. Ltd.) at an accelerating voltage of $80 \mathrm{KV}$.

\section{Results}

\section{Light microscopic findings}

In case 1 , the tumor tissue showed medullary growth with a rich distribution of delicate vascular networks. Individual neoplastic cells were cuboidal to polygonal and had slightly large ovoid nuclei. Narrow perivascular anuclear zone of fibrillary processes were seen sporadically (Fig. 1a). Abortive rosette-like structures were also detected. The remaining cases had solid nests which were separated each other by a rich fibrous stroma. Individual neoplastic cells had large ovoid nuclei and pale small cell bodies. Homer-Wright rosettes were seen in cases 2-5. Tubular structures (olfactory rosettes) were found in case 6 (Fig. 3a). Fibrillar processes were revealed in cases 1, 2, $5,6,7$ but not in the others (Figs. 1a, 3b).

\section{Immunohistochemical findings}

The findings are summarized in Table 3. As has been described in the previous section, all the cases satisfied the immunohistochemical criteria of Choi and Anderson, by having neuron specific enolase (NSE) positive tumor cell nests accompanied by $S-100$ positive sustentacular cells [3], but they were not consistently located at the periphery of some nests (Fig. 1b). In cases 1 and 5, sustentacular cells also exhibited immunoreactivity to glial fibrillary acidic protein (GFAP). Synaptophysin was detected in the tumor cell bodies or in their processes of all cases (Fig. 3-c). NF was detected in a few cells of case 6 and 7, but not in the cells of other cases. Small number of keratin positive cells were seen except in case 4 . Most of these keratin-positive cells were polygonal and were loosely aggregated in some nests (Fig. 3e). However, some of these cells had multipolar branching appearance and the appearance was not typical of the usual epithelial cells (Fig. 1d). Except for case 4, all cases had immunoreactivity to Ber-EP4 and it was demonstrated in more than one third of the tumor cells (Figs. 1c, 3d). The immunoreactivity was found on the cellular surface including fibrillary processes (Figs. 1c, 3d). LHRH was detected in the several tumor cells of cases 6 and 7 (Fig. 3f) but not in others. The immunoreactivity was confined to the somata and the pattern was similar to those seen in embryonic neurons migrate to the brain from the olfactory placode [13].

\section{Electron microscopic findings}

Processes with microtubules were shown in cases 1, 2 and 5-7 though the amount differed in each case. In cases 3 and 4, cytoplasmic preservation was quite poor in which the neuritic processes were not identified. Dense

Table 2. List of antibodies used for analysis

\begin{tabular}{lllll}
\hline \multicolumn{2}{l}{ antigen (clone/code) } & source & type of Ab. & dilution \\
\hline Keratin & (AE1/AE3) & Nichirei & mouse IgG & prediluted \\
NF & (2F11) & DAKO & mouse IgG & prediluted \\
EA & (Ber-EP4) & DAKO & mouse IgG & $1: 100$ \\
GFAP & $($ Z0334) & DAKO & rabbit Ig & $1: 400$ \\
S-100 & $($ Z0311) & DAKO & rabbit Ig & $1: 400$ \\
LHRH & (PS82) & SANBIO & rabbit Ig & $1: 800$ \\
NSE & (A0587) & DAKO & rabbit Ig & $1: 400$ \\
Synaptophysin & (A0010) & DAKO & rabbit Ig & $1: 150$ \\
\hline
\end{tabular}



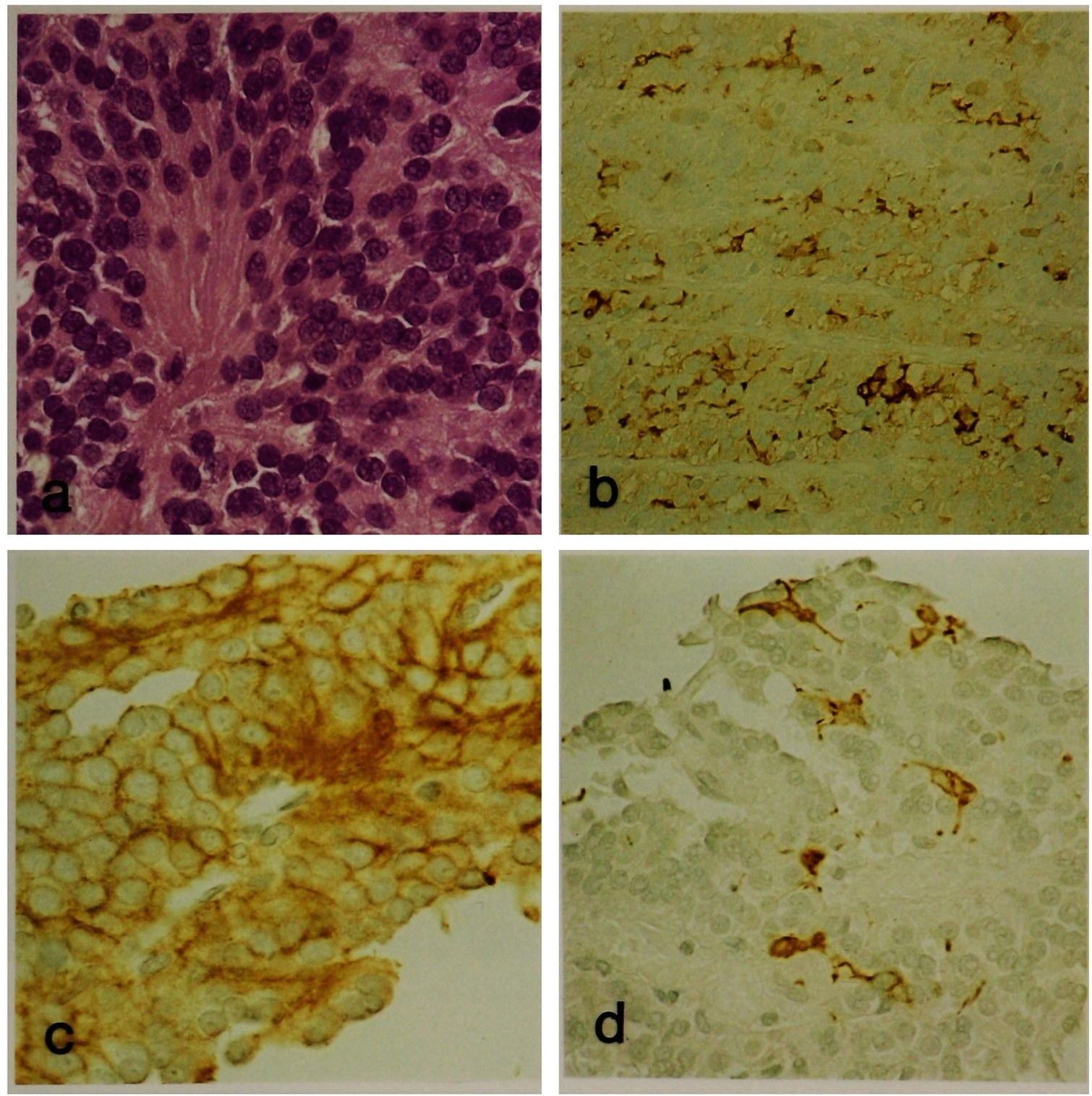

Fig. 1. Case 1 a: Densely packed small neoplastic cells with small perivascular anuclear zone of fibrillary processes. (H\&E) b: Random distribution of S-100 positive sustentacular cells. c: Widespread immunoreactivity to Ber-EP4 around cell bodies and in perivascular anuclear zone. d: Keratin-positive cells with short processes. (a, c $\times 400, \mathrm{~b} \times 150 \mathrm{~d} \times 320)$

:ore vesicles were detected in all cases, and were quite rich $\mathrm{n}$ cases 1 and 2 . In cases 6 and 7 too, such vesicles were ibundantly seen in some of the tumor cells, but quite parsely distributed in the remaining cases. In cases 1-5, he shapes of vesicles were spherical and regular in size, neasuring $90-120 \mathrm{~nm}$ in their diameters (Fig. 2-a, b). However, several tumor cells in cases 6 and 7 had nuch larger vesicles with various shapes. Their sizes also raried considerably and measured $130-840 \mathrm{~nm}$ in the argest diameters (Fig. 4-a, b). Small clear vesicles were llso seen in these cells (Fig. 4b). Microvilli were letected in some of the tumor cells of cases 2, and 5-7. In ase 6, abortive tubuli were formed by such tumor cells Fig. 4c). However, the morphology of the cells in such tubuli were not the same. Some of them had flask shape. Some others had several dark granules and their small cytoplasmic mass occasionally bulged out to the lumen. Desmosomal attachment was disclosed in cases 2, 5 and 6 (Fig. 4c).

\section{Discussion}

Based on ultrastructural findings, Silva et al. [19] proposed subdividing so-called olfactory neuroblastomas into true neuroblastomas and neuroendocrine carcinomas. They insisted neurite formation as an evidence of true neuroblastic differentiation and the presence of sustentacular cells as an evidence of early ganglionic differentia- 

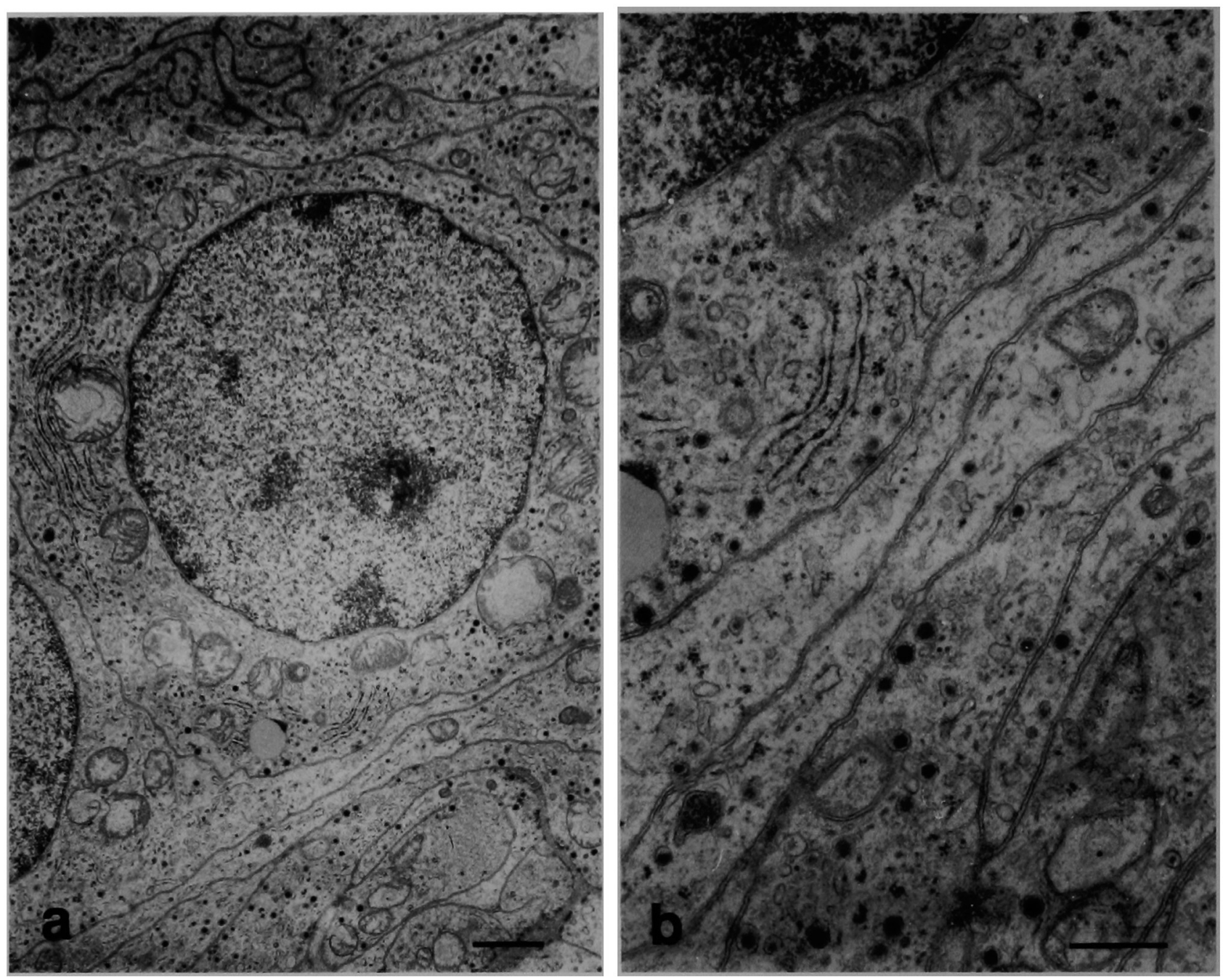

Fig. 2. Case $1 \mathrm{a}, \mathrm{b}$ : Tumor cell bodies and their processes rich in dense core vesicles (bars $=1 \mu \mathrm{m})$.

tion [19]. Subsequently, Choi and Anderson described the presence of S-100 positive sustentacular cells in NSEpositive cell nests as a diagnostic feature of the olfactory neuroblastoma [3] and all of our cases satisfied this diagnostic criterion. Synaptophysin and dense-core vesicles were also demonstrated in all cases. However, these immunohistochemical markers as well as S-100 positive sustentacular cells can be seen in neuroendocrine tumors of other organs, such as carcinoid of the respiratory tract, and dense core vesicles are frequently detected in such tumors $[1,4,24]$. Accordingly, these findings are not adequately substantial for a definite diagnosis of olfactory neuroblastoma and demonstration of neurites seems to be required for the confirmation of neuroblastic differentiation. In our series, five cases were shown to have neurites either by light microscopy or by electron microscopy and were confirmed to be neuroblastomas. However, in the remaining two cases, subtle neurites formation was not disclosed, though a satisfactory ultrastructural analysis could not be conducted because of poor fixation.

Our five cases with neurites exhibited widespread

Fig. 3. Case 6 a: Tubular structures within the tumor cell nest. (H\&E). b: Fibrillary processes in part of the tumor cell nests (H\&E). c: Synaptophysin in neoplastic cell processes. d: Immunoreactivity to Ber-EP4 in tumor cell processes. e: Aggregated keratin-positive cells scattered within the tumor nests. f: LHRH immunoreactivity in the tumor cells. $(a, c, d \times 250, e \times 125, f \times 320)$.

Fig. 4. Case 6 a: Neurites with microtubules around the tumor cell bodies. Irregularly shaped large dense core vesicles within the tumor cell bodies and in a few of neurites. b: A few of smaller clear vesicles coexisted with large dense core vesicles. c: Abortive lumina with microvilli and desmosomal attachment between the tumor cells. Small cytoplasmic mass bulged out to the lumen in the right side of the flask shaped cell. Electron-dense material was included in this cytoplasmic mass. (bars $\mathbf{a}, \mathbf{c}=1 \mu \mathrm{m}, b=0.5 \mu \mathrm{m}$ ) 

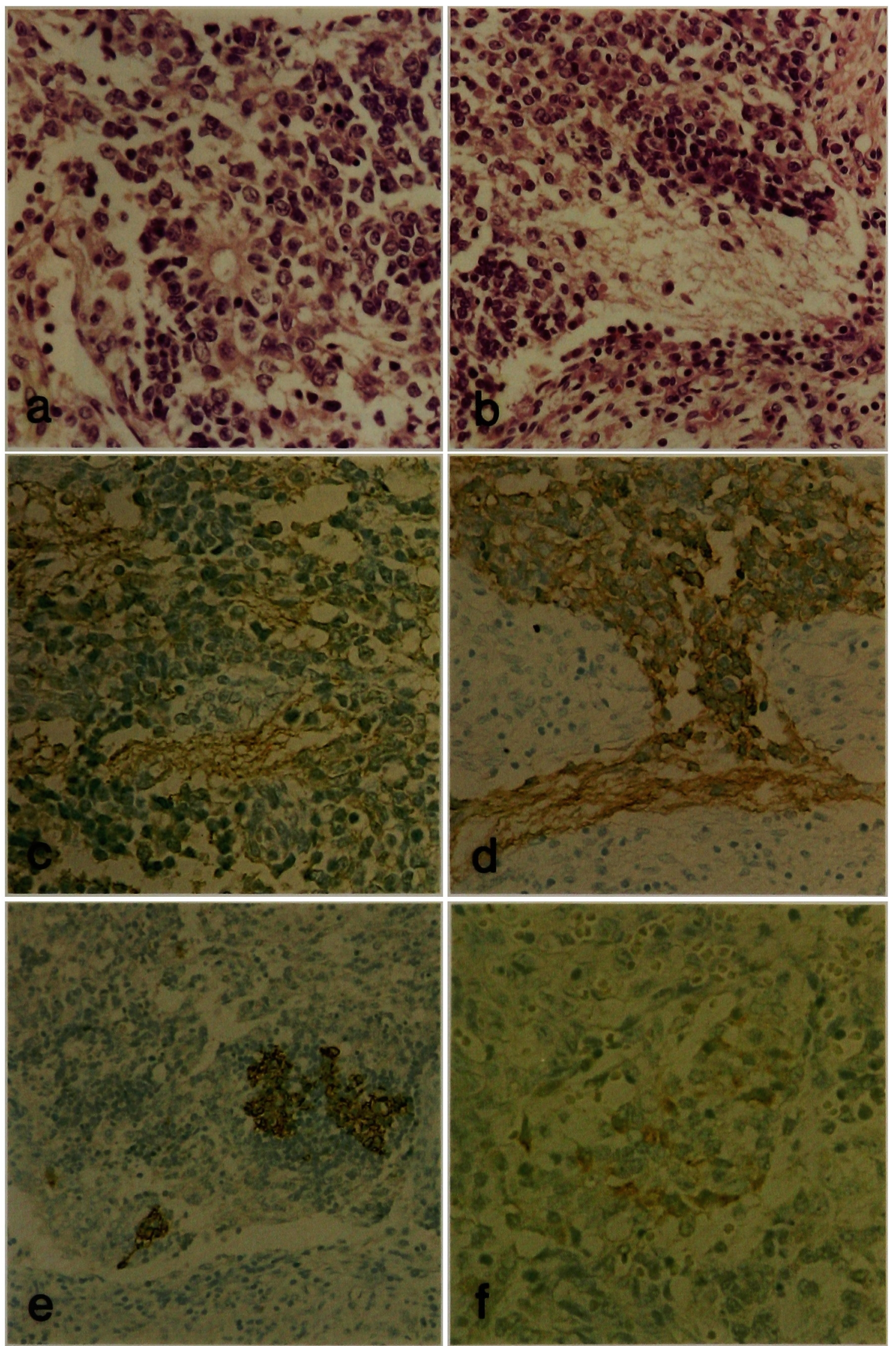

Fig. 3 


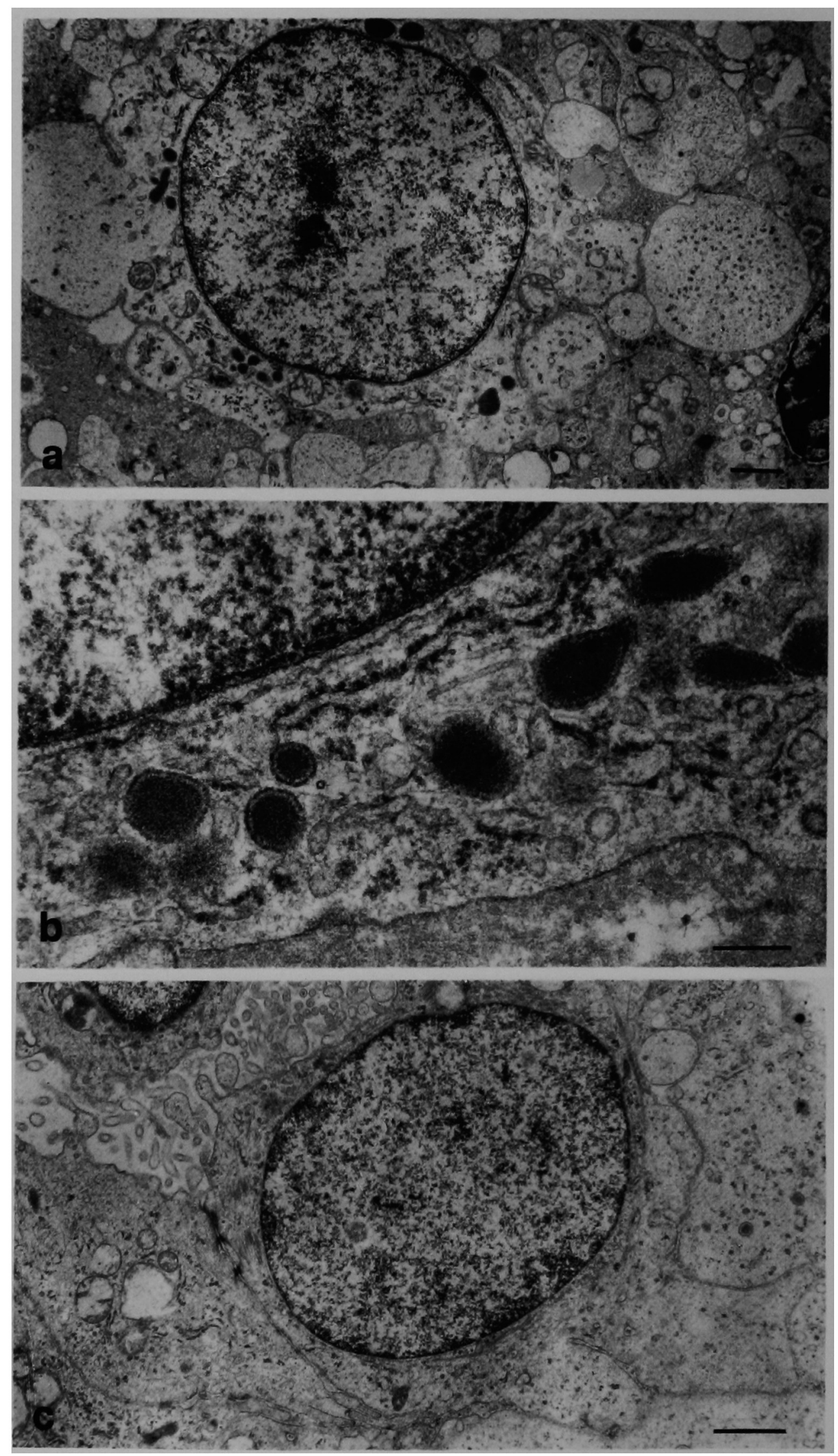

Fig. 4 
Table 3. Immunohistochemical profile of the tumors

\begin{tabular}{clllllllll}
\hline Case No. & Nrt & NF & NSE & Synapt & LHRH & S-100 & GFAP & Ber-EP4 & Kr \\
\hline 1 & $(+)$ & - & +++ & +++ & - & + & + & +++ & + \\
2 & $(+)$ & - & +++ & +++ & - & + & - & +++ & + \\
3 & $(-)$ & - & +++ & +++ & - & + & - & +++ & + \\
4 & $(-)$ & - & +++ & +++ & - & + & - & - & - \\
5 & $(+)$ & - & +++ & +++ & - & + & + & +++ & + \\
6 & $(+)$ & + & +++ & ++ & + & + & - & +++ & + \\
7 & $(+)$ & + & +++ & +++ & + & + & - & ++ & + \\
\hline
\end{tabular}

Nrt: neurite formation, NF: neurofilament, Synapt: synaptophysin, Kr: keratin. Nrt (Neurite formation) is evaluated qualitatively and the results are included in parenthesis. Other immunohistochemical results are evaluated quantitatively.

Ratio of positive cells: $+++=$ more than $2 / 3, \quad++=1 / 3-2 / 3, \quad+=$ less than $1 / 3$.

immunoreactivity to Ber-EP4, which is an antibody to $34 \mathrm{kDa}$ epithelial membrane glycoprotein. Although this antigen has been reported to be specific to epithelial cells and absent from neurons or neuroblastomas $[7,11]$, we have demonstrated its presence in all human olfactory placodal neurons during the early developmental stage and in the mature sensory neurons [13]. Accordingly, BerEP4 immunoreactivity in our five neuroblastic tumors seemed to reflect their true olfactory placodal origin. However, Ber-EP4 positive tumors without subtle neurite formation like case 3 are impossible to differentiate from neuroendocrine carcinoma. Tumors without Ber-EP4, such as case 4 also cannot be distinguished from paragangliomas or from neuroblastomas of non-olfactory origin, unless morphologic evidence of olfactory sensory neuronal differentiation or LHRH synthesis are demonstrated $[6,11,13,16,18,21,25]$.

Olfactory neuroblastomas have been described as having epithelial differentiation unlike neuroblastomas of other anatomical sites, especially in the esthesioneuroepithelioma subtype $[2,14,17,19]$. Tubular structure (olfactory rosette) is one of characteristic feature of this subtype $[6,19,21]$. Cilia or immature olfactory vesicle has been demonstrated in some of such tubuli and they were interpreted as immature sensory neuronal component $[6,19,21]$. In our case 6 too, tubular structures were demonstrated, but ciliated cells were not included in our electron microscopic specimens and evidence of classical olfactory sensory differentiation was not identified [11]. However, cells with microvilli were seen in this case and in cases $2,5,7$. Abortive tubuli were formed by these tumor cells in case 6 which were resembling to those described in a case of esthesioneuroepithelioma [21]. In previous reports, cells with microvilli has been interpreted as non-neuronal epithelial supporting cells (epithelial sustentacular cells) $[6,15,21]$. Some of the tumor cells with microvilli, especially in the abortive tubuli of case 6 seem to belong to epithelial sustentacular component because their ultrastructural findings resembled to the normal counterpart by having slender cell bodies, dense granules and occasional bulging of apical cytoplasmic mass toward the lumen [11]. However, demonstration of microvilli alone cannot be specified readily as evidence of definite epithelial sustentacular differentiation, because microvillar cells with flask shaped cell bodies has been identified as a subclass of olfactory sensory neuron [16]. In our cases, some of the tumor cells with microvilli were not so tall as usual sustentacular cells and had flask shape. Accordingly, it is not unnatural to suppose that sensory neuroblastic component is included in the tumor cells with microvilli, though further analysis is required to confirm such possibility.

Keratin has been demonstrated in some of olfactory neuroblastomas, especially in neuroepithelioma subtype, and has been interpreted as an evidence of definite epithelial differentiation [5, 21]. However, it is not unnatural for neoplastic olfactory neuroblasts to have keratin as suggested by Taxy et al. [22], because it is expressed in normal human olfactory placode-derived neurons during the early developmental stage [14]. Thus, keratin immunoreactivity in immature neoplastic cells, as in our five cases as well as Taxy's cases [22] is not contradictory to diagnosis of pure olfactory neuroblastoma and segregation of bipotential esthesioneuroepithelioma from pure olfactory neuroblastoma only by keratin immunohistochemistry is impossible from a practical point of view.

Olfactory placode, the presumptive source of this neoplasm, gives rise to LHRH neurons in addition to sensory neurons during the developmental stages $[13,18$, 25]. However, LHRH synthesis has not been reported in this tumor yet. Through our analysis, immunoreactivity to LHRH was demonstrated in cases 6 and 7, though the ratio of positive cells was not so high. Ultrastructurally, these two cases had tumor cells with dense core vesicles of various shapes and smaller empty vesicles as described and these findings were compatible with LHRH neurons [8, 20]. Accordingly, it was shown that differentiation to LHRH neuron was present in some of true olfactory neuroblastomas and this hormone seems to be useful to determine the olfactory placodal origin.

Although Trojanovski [23] described the presence of 
$\mathrm{NF}$ in the olfactory neuroblastoma, the incidence of positive staining was low in our five subtle olfactory neuroblastomas $(2 / 5)$ as described in previous report [22]. This low incidence of NF immunoreactivity may be related to the characteristics of the olfactory placodederived neurons: absence of immunoreactivity to several anti-NF antibodies in paraffin embedded olfactory nerve through its entire developmental course, though LHRH neuron has been found to gradually obtain immunoreactivity to these antibodies concomitant with maturation [13, 14]. To evaluate the precise incidence of NF immunoreactivity in this tumor, further large series of neuroblastomas with Ber-EP4 and/or LHRH should be analyzed.

Finally, we concluded, that olfactory neuroblastomas of true olfactory placodal origin do exist. Their immunohistochemical findings are different from neuroblastomas of any other portions and are similar to normal developing and mature olfactory placode-derived neurons. Diagnostic criteria of this tumor are as follows: 1) demonstration of neurites, 2) immunoreactivity to Ber-EP4 and/or LHRH or 3) electron microscopic demonstration of neoplastic sensory neurons with cilia and/or microvilli. Keratin could be expressed in this neuroblastoma as an embryonic phenotype of neurons of placodal origin [14]. Accordingly, it is impossible to segregate olfactory neuroepithelioma from neuroblastoma based on the findings of keratin immunohistochemistry.

\section{References}

1. Blobel, G. A., Gould, V. E., Moll, R., Inchul, L., Huszar, M., Geiger, B. and Franke, W. W.: Coexpression of neuroendocrine markers and epithelial cytoskeletal proteins in bronchopulmonary neuroendocrine neoplasms. Lab. Invest. 52; 39-51,1985.

2. Burger, P. C. and Scheithauer B. W.: Embryonal Tumors. In "Tumors of the Central Nervous System, Atlas of Tumor Pathology," third series Fascicles 10, Armed Forces Institute of Pathology/Washington D.C., 1994, pp. 193-225.

3. Choi, H.S. H. and Anderson, P. J.: Immunohistochemical diagnosis of olfactory neuroblastoma. J. Neuropathol. Exp. Neurol. 44; 18-31,1985.

4. Hammar, S. and Gould, V. E.: Neuroendocrine neoplasms. In "Pathology of Human Neoplasms" ed. By H. A. Azar, Raven Press/New York, 1988, pp. 333-404.

5. Kleihues, P., Burger, P. C. and Sheithauer, B. W.: Histological Typing of Tumours of the Central Nervous Tissue. World Health Organization International Classification of Tumours, second ed., Springer Verlag/Berlin, 1993.

6. Kudo, M., Aoyama, A., Tanaka, F. and Nakajima, T.: An electron microscopic investigation of esthesioneuro-epithelioma. Jpn. J. Clin. Pathol. XX; 754-763, 1972.

7. Latza, U., Niedobitek, G., Schwarting, R., Nekarda, H. and Stain, H.: Ber-EP4: new monoclonal antibody which distinguishes epithelia from methothelia. J. Clin. Pathol. 43; 213-219, 1990.

8. Liposits, Z., Merchenthaler, I. and Weetsel, W. C.: Morphological characterization of immortalized hypothalamic neurons synthesizing luteinizing hormone-releasing hormone. Endocrinol. 129; 1575-1583, 1991.
9. Miller, D. C., Goodman, M. L. and Pilch, B. Z.: Mixed olfactory neuroblastoma and carcinoma, a report of two cases. Cancer 54; 2019-2028, 1984.

10. Momburg, F., Moldenhauer, G., Haemerling, G. J. and Moeller, P.: Immunohistochemical study of the expression of a Mr. 34,000 human epithelium-specific surface glycoprotein in normal and malignant tissues. Cancer Res. 47; 2883-2891, 1987.

11. Moran, D. T., Rowley, J. C. III., Jafec, B. W. and Lovell, M. A.: The fine structure of olfactory mucosa in man. $J$. Neurocytol. 11; 721-746, 1982.

12. Morrison, E. E. and Costanzo, R. M.: Morphology of the human olfactory epithelium. J. Comp. Neurol. 297; 1-13, 1990.

13. Okabe, H., Okubo, T. and Ochi, Y.: Expression of an epithelial membrane glycoprotein by neurons arising from the human olfactory plate through development. Neurosci. 72; 579-584, 1996.

14. Okabe, H., Okubo, T., Adachi, H., Ishikawa, T. and Ochi, Y.: Immunohistochemical demonstration of keratin in human embryonic neurons arising from placodes. Brain and Development (in press).

15. Polazanis, B. M., Kabandris, P. M., Gigis, P. I. and Demetriu, T.: An electron microscopic study of human olfactory mucosa. J. Anat. 128; 77-83, 1979.

16. Rowley, III, J. C., Moran, D. T. and Jafek, B. W.: Peroxidase backfills suggest the mammalian olfactory epithelium contains a second morphologically distinct class of bipolar sensory neuron, the microvillar cell. Brain Res. 502; 387-400, 1989.

17. Russel, D.S. and Rubinstein, L. J.: Tumours of peripheral neuroblasts and ganglion. In "Pathology of Tumours of Central Nervous System" 5th ed., Edward Arnold/London, 1989, pp. 898-944.

18. Schwanzel-Fukuda, M. and Pfaff, D.W.: Origin of luteinizing hormone releasing hormone neurons. Nature 502; 387-400, 1989.

19. Silva, E. G., Buttler, J. J., Mackay, B. and Gepfert, H.: Neuroblastoma and neuroendocrine carcinomas of the nasal cavity. A proposed new classification. Cancer 50; 2388-2405, 1982.

20. Silverman, A. J.: Luteinizing hormone releasing hormone containing synapses in the diagonal bands and preoptic area of the guinea pig. J. Comp. Neurol. 227; 452-458, 1984.

21. Takahashi, H., Ohara, S., Yamada, M., Ikuta, F., Tanimura, K. and Honda, Y.: Esthesioneuroepithelioma: a tumor of true olfactory epithelium origin. An ultrastructural and immunohistochemical study. Acta Neuropathol. (Berl) 75; 147-155, 1987.

22. Taxy, J. B., Bharani, N. K., Mills, S. E., Fireson, H. F. and Gould, V.E.: The spectrum of olfactory neural tumors. A light microscopic, immunohistochemical and ultrastructural analysis. Am. J. Surg. Pathol. 10; 687-695, 1986.

23. Trojanovski, J. Q., Lee, V., Pilsbury, N. and Lee, S.: Neuronal origin of human esthesioneuroblastoma demonstrated with antineurofilament monoclonal antibodies. New Eng. J. Med. 307; 159-161, 1982.

24. Vyberg, M., Horn, T., Francis, D. and Askaa, J.: Immunohistochemical identification of neuron-specific enolase, synaptophysin, chromogranin an endocrine granule constituent in neuroendocrine tumors. Acta Histochemica. Suppl. 38; S179$181,1990$.

25. Wray, S., Nieberg, A. and Elkabes, S.: Spatiotemporal cell expression of luteinizing hormone releasing hormone in the prenatal mouse: evidence for an embryonic origin in the olfactory placode. Dev. Brain Res. 46; 309-318, 1989. 